\title{
A Rare Kind of Lymphoma in a Patient on Treatment With Two Different Biological Agents
}

\author{
Inesa ARSTIKYTE, ${ }^{1,2}$ Irena BUTRIMIENE, ${ }^{1,2}$ Agne PETRULIONIENE, ${ }^{1}$ Algirdas VENALIS ${ }^{1,2}$ \\ ${ }^{1}$ Vilnius University, Centre of Rheumatology, ${ }^{2}$ State Research Institute, Centre for Innovative Medicine, Research, Vilnius, Lithuania
}

\begin{abstract}
In this article, we present a rare case of cutaneous pseudolymphoma which developed after treatment with two biologics: infliximab and rituximab. Cutaneous pseudolymphoma should be considered in the differential diagnosis of B- or T-cell lymphoma, which may present not only with local lesions, but also systemic features like fever, weight loss, night sweating, fatigue, and tiredness. In our case, skin biopsy with immunohistochemistry confirmed diagnosis of cutaneous pseudolymphoma. Treatment with systemic corticosteroids was effective.

Keywords: Cutaneous pseudolymphoma; drug induced pseudolymphoma; infliximab; rituximab; treatment of pseudolymphoma.
\end{abstract}

Cutaneous pseudolymphoma (CPL) is a term used to indicate a group of skin disorders defined as benign lymphoprolipherative reactions that may simulate cutaneous malignant lymphomas clinically and/or histologically. ${ }^{1}$ These lesions represent a response to trauma, insect bites, stings, infections, tattoos, vaccinations, injection of foreign substances, pierced body jewelry, various drugs, and other undetermined stimuli. ${ }^{2-7}$ Not many papers are published regarding this disease since it is not commonly found in everyday clinical practice. It is essential to diagnose CPL as early as possible and differentiate it from skin Bor T-cell lymphoma.

\section{CASE REPORT}

A 60-year-old female with a nine year history of rheumatoid arthritis (RA) was treated in rheumatology center of university hospital in January 2011. Oral methotrexate $15 \mathrm{mg} /$ week and sulfasalazine $2000 \mathrm{mg} / \mathrm{d}$ combination with oral methylprednisolone $8 \mathrm{mg} /$ day and celexocib
$200 \mathrm{mg} / \mathrm{d}$ were started on diagnosis. From March 2005 to January 2009, infliximab 200 mg every eight weeks was administered in addition to oral methotrexate $15 \mathrm{mg} /$ week, methylprednisolone $8 \mathrm{mg} /$ day, and non-steroidal anti-inflammatory drugs due to active RA. During this treatment, patient's condition improved; however, low disease activity or remission was not achieved. Owing to poor treatment efficacy, in March 2009, after 46 months, infliximab was changed to rituximab at a dose of $1000 \mathrm{mg}$ according to drug prescription scheme.

In November 2010, after four cycles of rituximab $1000 \mathrm{mg}$ (two infusions per one cycle), butterfly type maculopapular rash presented on the face and symptoms of rhinitis appeared. The patient took antihistamine drug clemastine; however, the rash became more severe and saliva swallowing became difficult. Otorhinolaryngologist was unable to detect any pathology and no changes were observed in the sinus X-ray. Methotrexate and non-steroidal anti-inflammatory drugs were discontinued. The patient was admitted to the hospital with suspicion of lupus like syndrome.

Received: December 02, 2013 Accepted: July 21, 2014 Published online: January 13, 2015

Correspondence: Inesa Arstikyte, M.D. Department of Rheumatology, Vilnius University Hospital Santariskiu Clinics, LT-08661 Vilnius, Lithuania.

Tel: +370604 18279 e-mail: inesa.arstikyte@santa.It

@2015 Turkish League Against Rheumatism. All rights reserved. 
Anti-nuclear antibodies and antibodies against extractable nuclear antigen were absent at this time. Erythrocyte sedimentation rate was $20 \mathrm{~mm} / \mathrm{h}$ and immunoglobulin $\mathrm{E}$ level was normal. Other laboratory testswere unremarkable. Allergologist ruled out allergy. Subsequently, a skin biopsy was performed and a diagnosis of drug induced skin T-cell pseudolymphoma was established. Oral prednisolone $20 \mathrm{mg}$ daily was initiated following the recommendations of dermatologist and hematologist. Rapid resolution of skin rash and other symptoms was achieved. Afterwards, the patient was discharged taking only oral methylprednisolone $12 \mathrm{mg}$ daily. After one year, no skin lesions and partial remission of arthritis were observed, but it was followed by RA exacerbation and non-steroidal antiinflammatory drug reintroduction in addition to methylprednisolone $8 \mathrm{mg} /$ day.

\section{DISCUSSION}

The name for CPL has evolved from its first description "sarcomatosis cutis" to "pseudolymphoma of Spiegler-Friedt" in 1967, to the current term, "cutaneous lymphoid hyperplasia". Benign lymphoid hyperplasia (pseudolymphoma) has been reported to be found in the skin, lungs, orbit, conjunctiva, eyelids, gastrointestinal tract, liver, scrotum, vagina, and breast. $^{7}$

Cutaneous pseudolymphoma can be idiopathic or a reaction to various antigens. Etiologic factors of B- and T-cell pseudolymphomas are listed in Table 1. In most cases, etiologic factors of CPL remains unidentified.6,9 Drugs reported to cause lymphomatoid drug eruptions are listed in Table 2.9 Only few cases of CPL induced by biologics were reported (one case of etanercept, adalimumab, infliximab). ${ }^{10,11}$ Cases of lornoxicam, cyclosporine, parenteral gold therapy, and methotrexate induced CPL were introduced in the literature..$^{12-14}$

Cutaneous pseudolymphoma is not mentioned in the summary of infliximab or rituximab characteristics, although various skin rashes may occur as both drugs' adverse effect (for rituximab: more common in patients with non-Hodgkin's lymphoma and chronic lymphocytic leukemia, but not in RA patients). ${ }^{15,16}$ We were unable to find any publications about CPL induced by rituximab. Moreover, intralesional rituximab is reported to have some beneficial effect on CPL patients. ${ }^{17}$

Cutaneous pseudolymphoma refers to a heterogeneous group of benign reactive T-cell and B-cell lymphoproliferative processes of diverse causes, which can simulate cutaneous lymphomas in which the reactive inflammatory infiltrates may occasionally simulate lymphoma. ${ }^{1,2,18}$ The common feature of $\mathrm{CPL}$ that distinguishes it from other benign inflammatory cell infiltrates in the skin is the presence of variable numbers of medium to large sized lymphocytes, which may appear atypical, alongside many ordinary small lymphocytes and other inflammatory cells. Depending on the cause, this lymphocytic infiltrate may consist particularly of B- or T-cell, in most cases - mixture of $\mathrm{B}$ - and T-cells, macrophages and dendritic cells. ${ }^{2,18}$

Differential diagnosis includes B- or T-cell lymphoma, which may present not only with local lesions, but also systemic features like fever, weight loss, night sweating, fatigue, and tiredness. ${ }^{1}$ Skin biopsy with immunohistochemistry -considered to be gold standard - molecular, polymerase chain reaction, immunoglobulin's gene reorganization analysis and Southern blot method are essential for the differential diagnosis. ${ }^{1}$

Cutaneous pseudolymphoma occurs primary in adults (median age 34 years) and is slightly more common in females at a ratio of $2-3 .^{2}$ Most

\begin{tabular}{l} 
Table 1. Etiologic factors of B- and T-cell \\
pseudolymphomas ${ }^{[6,9]}$ \\
\hline Etiologic factors of B-cell pseudolymphoma \\
Borrelia burgdorferi \\
Varicella zoster \\
Insect bites \\
Tattoos \\
Medications (uncommon) \\
Acupuncture \\
Trauma \\
Vaccination (Bacille Calmette-Guerin, diphtheria, tetanus and \\
pertussis, antitetanus, hepatitis B etc.) \\
Golden jewelry \\
Idiopathic \\
Etiologic factors of T-cell pseudolymphoma \\
Medications (most common: anticonvulsants, angiotensin- \\
converting ferment inhibitors) \\
Allergic contact dermatitis \\
Insect bites \\
Ultraviolet rays \\
Human immunodeficiency virus \\
Idiopathic
\end{tabular}


Table 2. Drugs reported to cause T-cell cutaneous pseudolymphoma ${ }^{[9]}$

\begin{tabular}{ll}
\hline Class & Drugs \\
\hline Anticonvulsants & $\begin{array}{l}\text { Phenytoin, carbamazepine, mephenytoin, trimethadione, } \\
\text { phenobarbital, primidone, butobarbitol, methsuximide, } \\
\text { phensuximide }\end{array}$ \\
Antipsychotics & Chlorpromazine, thioridazine, promethazine \\
Angiotensin-converting enzyme inhibitors & Captopril, enalapril, benazepril \\
Beta-blockers & Atenolol, labetalol \\
Calcium channel blockers & Verapamil, diltiazem \\
Diuretics & Moduretic, hydrochlorothiazide \\
Cytotoxics & Cyclosporine, methotrexate \\
Antirheumatics & Gols, salicylates, phenacetin, D-penicillamine, allopurinol, \\
& non-steroidal anti-inflammatory drug \\
Antibiotics & Penicillin, dapsone, nitrofurantoin \\
Antidepressants & Fluoxetine, doxepin, desipramine, amitriptyline \\
& hydrochloride, lithium \\
Anxiolytics & Benzodiazepines (clonazepam, lorazepam) \\
Histamine type 2 receptor antagonists & Diphenhydramine \\
Antiarrhythmics & Cimetidine, ranitidine \\
Topical agents & Mexiletine chloride, procainamide \\
Sex steroids & Menthol, etheric plant oil \\
Lipid-lowering agents & Estrogen, progesterone \\
& Lovastatin \\
\end{tabular}

cases are asymptomatic solitary or focal clusters of papules/nodules. These can appear on any area of the skin, most commonly the face or scalp. The lesions rarely present in a segmental or disseminated fashion. Constitutional symptoms and lymphadenopathy are usually absent, as well as extracutaneous physical findings or laboratory abnormalities. ${ }^{18}$

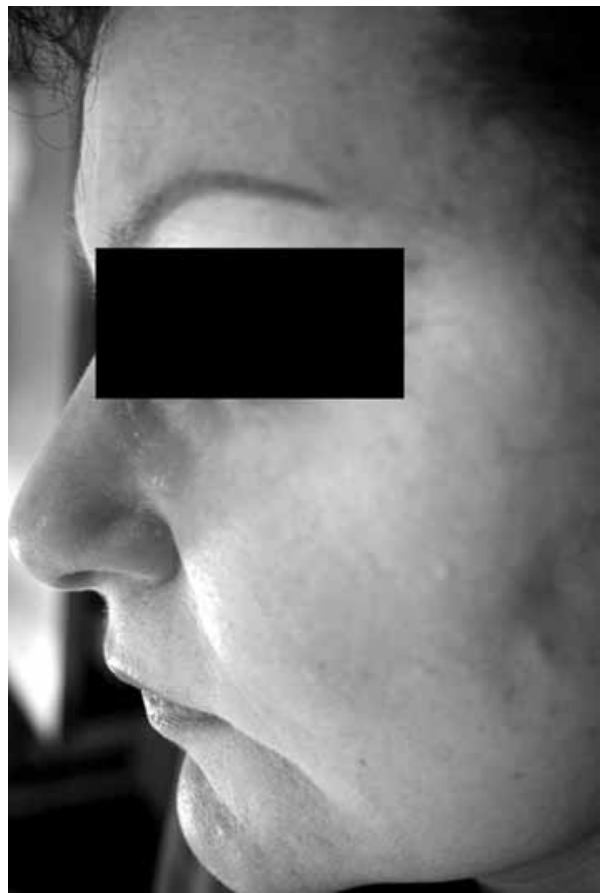

Figure 1. Lesions on left side of patient's face.

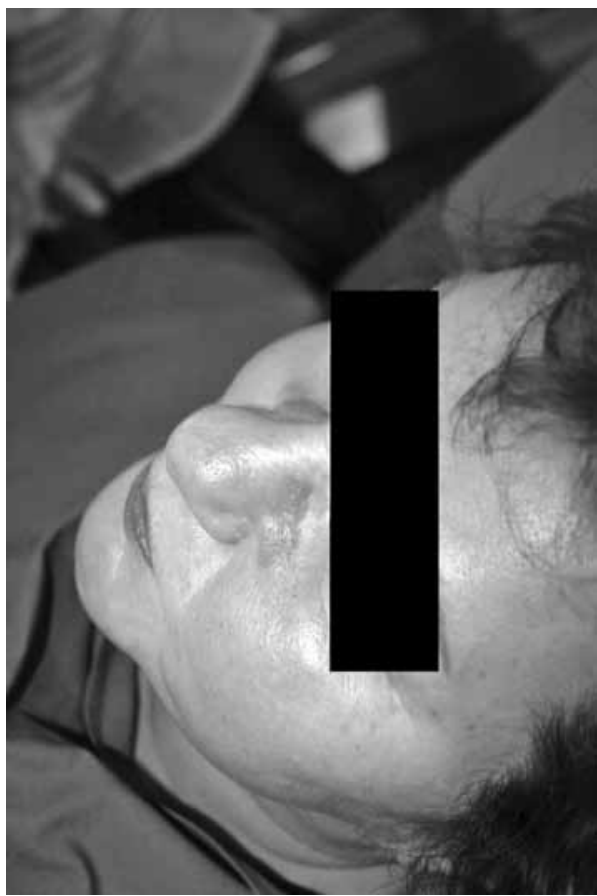

Figure 2. Lesions on the patient's face. 
Cutaneous pseudolymphoma often resolves itself spontaneously but, in persistent lesions, association with malignant lymphoma is possible. If the etiology is clearly identified, treatment confines upon avoidance of the cause. If offending agent is removed, the disease most often resolves spontaneously in one to eight weeks. ${ }^{7}$ When the cause cannot be detected, the clinical course varies, but it tends to be chronic and indolent. In many cases, however, treatment with variety of therapies, including ultraviolet $\mathrm{B}$ light phototherapy, psoralen and ultraviolet A light therapy, topical 5-aminolevulinic acid-based photodynamic therapy, antibiotics, systemic or intralesional corticosteroids, azathioprine, cyclosporine, interferon alpha- $2 \mathrm{~b}$, excision or radiotherapy are instituted with variable success. ${ }^{7,19,20}$

\section{Declaration of conflicting interests}

The authors declared no conflicts of interest with respect to the authorship and/or publication of this article.

\section{Funding}

The authors received no financial support for the research and/or authorship of this article.

\section{REFERENCES}

1. Rijlaarsdam JU, Willemze R. Cutaneous pseudolymphomas: classification and differential diagnosis. Semin Dermatol 1994;13:187-96.

2. Nihal M, Mikkola D, Horvath N, Gilliam AC, Stevens SR, Spiro TP, et al. Cutaneous lymphoid hyperplasia: a lymphoproliferative continuum with lymphomatous potential. Hum Pathol 2003;34:617-22.

3. Chiang $C$, Romero L. Cutaneous lymphoid hyperplasia (pseudolymphoma) in a tattoo after far infrared light. Dermatol Surg 2009;35:1434-8.

4. Ziemer $\mathrm{M}$, Eisendle $\mathrm{K}$, Müller $\mathrm{H}$, Zelger $\mathrm{B}$. Lymphocytic infiltration of the skin (JessnerKanof) but not reticular erythematous mucinosis occasionally represents clinical manifestations of Borrelia-associated pseudolymphoma. Br J Dermatol 2009;161:583-90.

5. Atalar H, Sarifakioglu E, Dener C, Yanik B, Koktener A, Bayrak R. Cutaneous lymphoid hyperplasia and reactive lymphadenopathy induced by hepatitis $B$ vaccination. Eur J Dermatol 2008;18:188-9.

6. Nnebe NV, Woon C, Haines S, Dayton V, Weigel BJ. Cutaneous pseudolymphoma: an unusual presentation of a scalp mass. Pediatr Blood Cancer 2009;52:283-5.
7. Ploysangam $\mathrm{T}$, Breneman DL, Mutasim DF. Cutaneous pseudolymphomas. J Am Acad Dermatol 1998;38:877-95.

8. McElroy MK, Kulidjian AA, Sumit R, Weidner N. Benign lymphoid hyperplasia (pseudolymphoma) of soft tissue. Hum Pathol 2011;42:1813-8.

9. Guis S, Schiano de Colella JM, Bonnet N, AndracMeyer L, Balandraud N, Mattei JP, et al. Cutaneous pseudolymphoma associated with a TNF-alpha inhibitor treatment: etanercept. Eur J Dermatol 2008; 18:474-6.

10. Imafuku S, Ito K, Nakayama J. Cutaneous pseudolymphoma induced by adalimumab and reproduced by infliximab in a patient with arthropathic psoriasis. Br J Dermatol 2012;166:675-8.

11. Delaporte E, Catteau B, Cardon T, Flipo RM, LecomteHoucke $\mathrm{M}$, et al. Cutaneous pseudolymphoma during treatment of rheumatoid polyarthritis with low-dose methotrexate. Ann Dermatol Venereol 1995;122:521-5.

12. Kalimo K, Räsänen L, Aho H, Mäki J, Mustikkamki UP, Rantala I. Persistent cutaneous pseudolymphoma after intradermal gold injection. J Cutan Pathol 1996;23:328-34.

13. Stavrianeas NG, Katoulis AC, Bozi E, ToumbisIoannou E, Kanelleas AI, Makris M, et al. Cutaneous pseudolymphoma following administration of lornoxicam. Acta Derm Venereol 2007;87:453-5.

14. Bagot M, Wechsler J, Perrussel M, Robbiola O, Debure C, Dubertret L. Pseudolymphoma induced by cyclosporin. Ann Dermatol Venereol 1989;116:894-6.

15. Summary of product (MabThera) characteristics. Available from: http://www.ema.europa.eu/docs/en GB/document_library/EPAR_-_Product_Information/ human/000165/WC500025821.pdf.

16. Summary of product (Remicade) characteristics. Available from: http://www.ema.europa.eu/docs/en GB/document_library/EPAR_-_Product_Information/ human/000240/WC500050888.pdf.

17. Martin SJ, Duvic M. Treatment of cutaneous lymphoid hyperplasia with the monoclonal anti-CD20 antibody rituximab. Clin Lymphoma Myeloma Leuk 2011;11:286-8.

18. Arai E, Shimizu M, Hirose T. A review of 55 cases of cutaneous lymphoid hyperplasia: reassessment of the histopathologic findings leading to reclassification of 4 lesions as cutaneous marginal zone lymphoma and 19 as pseudolymphomatous folliculitis. Hum Pathol 2005;36:505-11.

19. Dionyssopoulos A, Mandekou-Lefaki I, Delli FS, Kourtis D, Nikolis A, Dionyssopoulou E, et al. T- and B-cutaneous pseudolymphomas treated by surgical excision and immediate reconstruction. Dermatol Surg 2006;32:1526-9.

20. Tomar S, Stoll HL, Grassi MA, Cheney R. Treatment of cutaneous pseudolymphoma with interferon alfa- $2 b$. J Am Acad Dermatol 2009;60:172-4. 